\title{
Índice de Qualidade de Via Ciclável \\ Percebido pelo Usuário (IQVCPU) em Brasília \\ DF - Brasil: Desenvolvimento e Modelagem Utilizando Equações Estruturais
}

\author{
User Perceived Cycle Quality Index (IQVCPU) in Brasília DF - \\ Brazil: Development and Modeling Using Structural Equations
}

Amanda Basílio Romano [a] [D], Pastor Willy Gonzales Taco [b] [D],

Zuleide Oliveira Feitosa [c] [D], José Carlos Mota [c] [i]

[a] Universidade de Brasília, Departamento de Engenharia Civil e Ambiental, Faculdade de Tecnologia, Brasília, DF, Brasil

[b] Universidade de Brasília, Programa de Pós-Graduação em Transportes (PPGT), Departamento de Engenharia Civil e Ambiental, Faculdade de Tecnologia, Brasília, DF, Brasil

[c] Universidade de Aveiro, Departamento de Ciências Sociais, Políticas e do Território, Aveiro, Portugal

Como citar: Romano, A. B., Taco, P. W. G., Feitosa, Z. O., \& Mota, J. C. (2021). Índice de Qualidade de Via Ciclável Percebido pelo Usuário (IQVCPU) em Brasília DF - Brasil: Desenvolvimento e Modelagem Utilizando Equações Estruturais. urbe. Revista Brasileira de Gestão Urbana, v.13, e20200307. https://doi.org/10.1590/2175-

3369.013.e20200307

\section{Resumo}

Este estudo tem como objetivo desenvolver um Índice de Qualidade da Via Ciclável Percebida pelo Usuário (IQVCPU) e com isso avaliar os fatores que influenciam na qualidade do deslocamento das vias cicláveis implantadas em Brasília DF, Brasil, utilizando a Modelagem por Equações Estruturais (Structural Equation Model - SEM). Por meio de uma Revisão Sistemática da Literatura, foram identificados os fatores utilizados para mensurar a qualidade do deslocamento, nos métodos já existentes, considerando a infraestrutura cicloviária. Com os fatores mais relevantes, foram definidas e analisadas as variáveis latentes (construtos) relacionadas por indicadores que configuraram o IQVCPU. A coleta dos dados foi realizada por meio de inquérito com aplicação on-line para usuários de bicicleta de Brasília DF. A Modelagem com SEM determinou que o Índice, na visão do usuário, explica o seu uso em até $36,48 \%$ e que são sete os fatores que influenciam a qualidade do deslocamento das vias cicláveis. Concluiu-se que o conhecimento desses fatores e do IQVCPU pode promover o uso seguro da bicicleta como modo de transporte em áreas urbanas e subsidiar as políticas públicas da ciclomobilidade.

Palavras-chave: Bicicleta. Infraestrutura Cicloviária. Via Ciclável. Índice de Qualidade. Equações Estruturais.

ABR é engenheira civil, bacharela em Engenharia Civil, e-mail: amandaromano27@gmail.com

PWGT é engenheiro civil, doutor em Transportes, e-mail: pwgtaco@gmail.com

ZOF é psicóloga, doutora em Transportes, e-mail: feitosa@ua.pt

JCM é urbanista, doutor em Ciências Socias, e-mail: jcmota@ua.pt 


\section{Abstract}

This study aims to define the "Index of Bicycle Lanes Quality Perceived by Users" called "iBikeLane" for the purpose of evaluate the factors that influence the quality of bicycle trips in Brasilia, Brazil. To achieve this goal, a systematic literature review was conducted to identify, in the existing methods, factors that allows measure the bicycle trip quality. From the most relevant factors we define and analyze the latent variables (constructs) related by indicators that make up the iBikeLane. The data was collected through an on-line survey applied to cyclists of Brasilia. The analysis was carried out by the Structural Equation Model (SEM). The modelling determined that the index, in the perspective of the users, explain its use by up $36.48 \%$. We also found seven factors that influence the quality of the trips in the bicycle lanes. We concluded that knowing the factors and the iBikeLane allows promoting the safe use of bicycle as a mode of transport in urban areas and subsidizing de development of sustainable mobility policy.

Keywords: Bicycle. Cycle Infrastructure. Cycle Path. Quality Index. Structural Equations.

\section{Introdução}

0 crescimento do uso da bicicleta é um fenômeno em expansão nos centros urbanos (Useche et al., 2018), apesar da preponderância do automóvel como modo de transporte individual (Feitosa, 2017). Nos mais diferentes contextos, sejam universitários ou nas comunidades em geral, os indivíduos, com diferentes estilos de vida, educação, cultura e atitudes, têm adotado hábitos que incluem o uso da bicicleta como opção de transporte ou de lazer e saúde (Kelarestaghi et al., 2019). Por exemplo, nas cidades brasileiras, diante do crescimento não planejado e da criação de bairros informais, as bicicletas são um meio de transporte individual de baixo custo, não poluente e utilizam energia renovável (Ferreira, 2007). São versáteis e incentivam o cuidado com a saúde (Leiva \& Barbosa, 2006). Tal fato, por um lado, pode produzir inclusão social (Largura, 2012; Romano, 2017) e, por outro, pode produzir a desigualdade social (Gutiérrez \& Reyes, 2017) uma vez que a geografia urbana e as políticas sociais de distribuição do uso do solo nem sempre são adequadas para as diferentes classes sociais (Mota et al., 2019).

No entanto, observa-se que as desigualdades sociais diminuem à medida que as políticas de distribuição do uso do solo começam a mudar, uma vez que o aumento das ciclovias, nas últimas décadas, é resultado da busca por soluções sustentáveis de mobilidade (Silva, 2015; SLoCaT, 2018). Nesse cenário, o crescimento do uso da bicicleta é um fenômeno em expansão (Useche et al., 2018) apesar da preponderância do automóvel como modo de transporte individual nos centros urbanos (Feitosa, 2017). Dessa maneira, para Pezzuto (2002) os modos de transporte ativos, em particular a bicicleta, podem ter papel de destaque. Assim, a presença de infraestrutura para uso da bicicleta, como ciclovias, pistas e estacionamento, afeta positivamente o comportamento do ciclista (Buehler \& Pucher, 2012; Yang et al., 2019). Para além das dificuldades ambientais e dos vieses do planeamento urbano, os gestores urbanos estão se deparando com um interesse popular crescente no uso da bicicleta, tanto em viagens para o trabalho, para a escola, como para atividades relacionadas à saúde e à recreação. Assim, andar de bicicleta está se tornando, de forma gradual, um modo de transporte urbano mais sustentável, inclusive para o turismo (Pucher \& Buehler, 2017; Terh \& Cao, 2018; Zhou et al., 2020). Além disso, promover o uso da bicicleta reforça a preocupação dos gestores em oferecer alternativas de transportes diferentes do automóvel; uma vez que razões para o uso e a distribuição do solo incluem as preocupações econômicas e ambientais (Sousa, 2012; SLoCaT, 2018).

No caso de Brasília - Distrito Federal (DF), a promoção da bicicleta como alternativa de transporte sustentável teve sua origem em 2004, com a criação do Programa Cicloviário do DF. Em 2007, o Programa passou a se chamar PEDALA-DF, com a meta de construir 600 quilômetros de infraestrutura cicloviária no DF e assim diminuir o número de ciclistas mortos em acidentes de trânsito (Romano, 2017). Em 2009, com a Lei no 4.397/09, foi criado o Sistema Cicloviário do DF (Brasil, 2009) e, em agosto de 2011, com o Decreto no 33.158, foi instituído o Comitê Gestor da Política de Mobilidade Urbana por Bicicleta no DF (Brasil, 2011); e, assim, o PEDALA-DF passou a ser conhecido como Plano de Mobilidade por Bicicleta do DF (Distrito Federal, 2014; Velloso, 2015). Como 
resultado dessas ações, no período de 2003 a 2013 o número de ciclistas mortos em acidentes de trânsito nas vias do DF caiu de 69 para 32 (Distrito Federal, 2020), uma redução de 46,37\% em dez anos.

Ainda, em maio de 2014, diante dos novos avanços tecnológicos e das experiências nacionais e internacionais, o Governo do Distrito Federal lançou o Sistema de Bicicletas Públicas, também conhecido como Sistema de Bicicletas Compartilhadas (SBC). Em 2014, o sistema possuía 77.536 usuários cadastrados e, em 2019, esse número chegou a 211.122 usuários e 1.400 .000 viagens de bicicletas realizadas, com 48 estações espalhadas pelo Plano Piloto e 2 estações infantis; com 553,95 km de faixas próprias para bicicletas, em 28 Regiões Administrativas (Distrito Federal, 2017). Embora o SBC tenha sido implantado com o intuito de possibilitar a integração ao transporte público e dar multifuncionalidades aos usuários no deslocamento urbano, ainda há outros fatores negativos, como, por exemplo, a descontinuidade das ciclovias e a insegurança pública que ainda estão presentes no dia a dia dos ciclistas (Lourenço, 2015; Romano, 2017). Sabe-se, também, que o crescimento da infraestrutura para bicicleta, de certa forma, promove o seu uso. Dados da Pesquisa Domiciliar de Mobilidade Urbana, realizada pelo Metrô-DF, em 2016, mostraram que $1,74 \%$ das viagens realizadas utilizaram como modo de transporte a bicicleta (Distrito Federal, 2018a). Já segundo a Pesquisa Distrital por Amostra de Domicílios de 2018, observou-se que 2,1\% dos moradores/habitantes utilizaram a bicicleta como principal meio de transporte para ir ao trabalho e $1,1 \%$ para ir à escola/ao curso (Distrito Federal, 2018b).

Nesse contexto do crescimento da oferta de infraestrutura ciclável própria para bicicletas, da promoção do SCB e do aumento do uso como modo de transporte, o presente artigo tem como objetivo desenvolver um Índice de Qualidade da Via Ciclável Percebida pelo Usuário (IQVCPU). 0 Índice permitirá avaliar os fatores que influenciam na qualidade do deslocamento das vias cicláveis implantadas em Brasília — DF, Brasil, utilizando a Modelagem por Equações Estruturais (Structural Equation Model - SEM). Desse modo, o estudo está dividido em seis seções. Seguida da introdução, a seção 2 apresenta os métodos para análise das vias cicláveis e os fatores que influenciam o uso do sistema ciclável. Na seção 3, descreve-se o método delineado para a execução da pesquisa e a análise dos dados por meio de equações estruturais. Na seção 4 , discorre-se detalhadamente sobre os principais resultados encontrados. Na seção 5, faz-se a discussão dos resultados com base na revisão da literatura. Por fim, encerra-se o artigo na seção 6 que contempla as principais considerações e conclusões identificadas.

\section{Métodos para análise das vias cicláveis e fatores que influenciam o uso do sistema ciclável}

Na literatura nacional e internacional são vários os métodos existentes para análise das vias cicláveis. Entre os estudos nacionais, destacam-se o trabalho sobre nível de qualidade da rota para ciclistas — NQRC (Leiva \& Barbosa, 2006); o Índice Cicloviário de Largura (2012); o Índice de Condição da Rede Cicloviária Verde - ICRCV (Schubert, 2016); o Índice Geral de Adequação do Segmento (Campos \& Cardoso, 2016). Dentre os estudos internacionais, aponta-se o Bicycle Safety Index Rating - BSIR (Davis, 1987); o Florida Roadway Condition Index - RCI (Epperson, 1994); o Bicycling Stress Levels (Sorton \& Walsh, 1994); o Bicycle Level of Service - BLOS (Landis et al, 1997); Bicycle Environmental Quality Index - BEQI (San Francisco Department of Public Health, 2009).

Quanto aos fatores que influenciam no comportamento da escolha da via ciclável, a literatura aponta para os fatores de viagem (Romano, 2017) tais como distância, tempo e motivo (Pezzuto, 2002; Chapadeiro, 2011; Winters et al., 2011; Segadilha \& Sanches, 2012; Sousa, 2012); para os fatores ambientais, como clima, topografia e relevo (Pezzuto, 2002; Chapadeiro, 2011; Winters et al., 2011; Segadilha \& Sanches, 2012; Sousa, 2012; Calvey et al., 2015); para os fatores dos usuários como características do indivíduo, preferências e percepções (Pezzuto, 2002; Chapadeiro, 2011; Segadilha \& Sanches, 2012; Sousa, 2012; Calvey et al., 2015); para fatores do modo de transporte, quais sejam, velocidade da bicicleta, o custo do modo de transporte e a disponibilidade de alternativas (Pezzuto, 2002; Chapadeiro, 2011; Winters et al., 2011; Calvey et al., 2015). Também o tráfego, como classificação e composição do tráfego (Pezzuto, 2002; Winters et al., 2011; Segadilha \& Sanches; Chataway et al., 2014); a infraestrutura, como característica da 
via ciclável, percepção e configuração da infraestrutura, configuração das medidas de segurança viária (Pezzuto, 2002; Winters et al., 2011; Segadilha \& Sanches, 2012; Chataway et al., 2014; Calvey et al., 2015; Romano, 2017); as variáveis socioculturais (cultura de mobilidade sustentável; política de mobilidade sustentável, e hábito) (Pezzuto, 2002; Chapadeiro, 2011; Sousa, 2012; Feitosa, 2017).

Romano (2017) realizou uma Revisão Sistemática da Literatura sobre os fatores que influenciam o uso do sistema cicloviário, determinando 7 categorias (do usuário, socioculturais, ambientais, da viagem, do tráfego, da infraestrutura e do modo de transporte) e 31 fatores (Figura 1).

\section{FATORES QUE INFLUENCIAM O USO DO SISTEMA CICLOVIÁRIO}

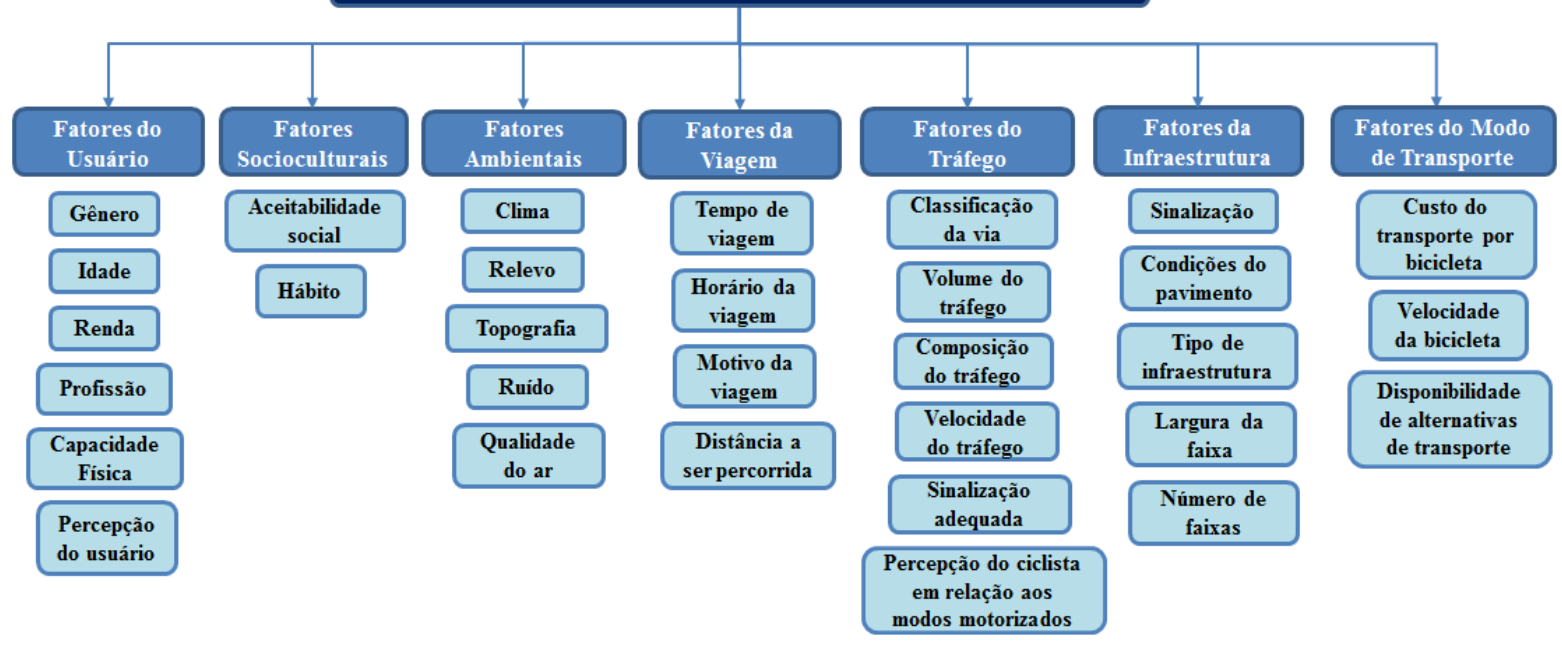

Figura 1- Fatores que influenciam o uso do sistema cicloviário: do usuário, socioculturais, ambientais, de viagem, do tráfego, da infraestrutura, do modo de transporte. Fonte: adaptado de Romano (2017).

Nos estudos do comportamento, inclusive do comportamento de viagem, a modelagem é frequentemente empregada. Por exemplo, Du et al. (2020), por meio de uma revisão da literatura, estabelecem que a abordagem metodológica mais recorrente para explicar o comportamento ciclável é a frequência de uso da bicicleta e a modelagem. Dessa maneira, empregam-se, na análise dos dados, a técnica de logit binário, logit multinomial, o modelo analítico e o modelo por equações estruturais (SEM). Ainda, Kelarestaghi et al. (2019) e Sun et al. (2019) avaliam a validade, a confiabilidade, por meio da análise fatorial confirmatória (CFA), para depois analisar o modelo proposto e os efeitos diretos dos fatores que influenciam a via ciclável. A significância estatística do modelo é realizada com a metodologia do bootstrapping.

No caso do estudo de Kelarestaghi et al. (2019), a amostra foi constituída por 780 usuários de bicicleta, dos quais $45 \%$ eram alunos de graduação. A faixa que mais utilizava a bicicleta ficava entre os 25 e os 36 anos. 0 procedimento de análise fatorial aplicado mostrou que, das 37 variáveis analisadas, 31 foram confirmadas como potenciais variáveis latentes. A modelagem por equação estrutural mostrou que as variáveis testadas são preditoras da frequência de comportamento ciclável. Já no estudo de Sun et al. (2019), com uma amostra de 874 ciclistas, tais autores identificaram que as mulheres (52\%) utilizavam mais a bicicleta do que os homens (48\%) e que pessoas de menor renda (37\%), em torno de três salários mínimos, foram as que mais utilizaram a bicicleta. A análise dos resultados se mostrou de acordo ao esperado e a confiabilidade da medida está dentro da estimativa estatística, variando entre 0,894 a 0,933 , bem como os indicadores do modelo $\chi^{2}$ 716086, df 309; $\mathrm{p}<0,001 ; \chi^{2} / \mathrm{df} 2.317$; GFI 0,941; CFI 0,975; SRMR 0,024; RMSEA 0,039)1.

A pesquisa realizada, por meio do estudo proposto, testou o modelo conceitual de modelos de estimação por meio do qual se atentou para a entrada dos dados, para a matriz de covariância (CB-SEM) ou matriz de variância (PLS-SEM). CB-SEM é a modelagem por equações estruturais baseada em covariância e PLS-SEM é a modelagem por equações estruturais baseada nos mínimos quadrados parciais (Ramirez et al.,

\footnotetext{
${ }_{1} \mathrm{x}^{2}$ (qui-quadrado); df (graus de liberdade); $\mathrm{p}$ (p-valor); x2/df (razão estatística de resposta ao item de variáveis dicotômicas); GFI (Índice de Qualidade de Ajuste); CFI (Índice de Ajuste Comparativo); RMSR (Raiz de Resíduo Quadrático Médio); RMSEA (Raiz do Erro Quadrático Médio de Aproximação).
} 
2014; Tenenhaus, 1998). A propósito do estudo realizado, notou-se que os modelos baseados no PLS maximizam o poder preditivo das variáveis latentes. 0 modelo estrutural comporta muitos construtos e muitas variáveis, por isso requer uma amostra pequena e os dados são normalmente distribuídos. Diferente do PLS, os cálculos estatísticos em CB-SEM permitem testar a teoria, confirmar a teoria, ou comparar teorias alternativas (Ramirez et al., 2014). Além do mais, o CB-SEM trabalha com análise estrutural de covariância e o PLS-SEM com a estimação dos mínimos quadrados parciais (Sarstedt et al., 2014). Segundo, optou-se pelo uso da análise dos dados por meio do PLS devido a sua adequação ao desenho da pesquisa e aos seus objetivos como um todo. Portanto, conforme foi argumentado, o método de análise estatística PLS-SEM foi adotado uma vez que permite a análise multivariada de dados para avaliar, simultaneamente, relações entre múltiplos construtos, visto que este é um dos objetivos da pesquisa.

\section{Método utilizado para construção do Índice de Qualidade da Via Ciclável Percebido pelo Usuário (IQVCPU)}

Método desenhado para a elaboração do IQVCPU está ilustrado passo a passo na Figura 2. Apresenta-se cada uma das etapas do método para a construção do referido Índice a partir dos fatores que influenciam na qualidade percebida. Dessa maneira, na Etapa 1, os fatores que influenciam o uso do sistema cicloviário foram obtidos na revisão da literatura (Romano, 2017). A partir das sete categorias e dos 31 fatores são formuladas as ações que avaliam a via ciclável, seguindo os critérios estabelecidos por Romano (2017). Por exemplo, considerando os fatores, viagem e ambiente, que influenciam o uso do sistema cicloviário, apresentados na Figura 1, são construídas as ações que avaliam o deslocamento das vias cicláveis, como descrito a seguir na Tabela 1. De posse das ações, é elaborado o Mapa Cognitivo de relação entre os meios e os fins das ações e os fatores evidenciados na Tabela 2. Logo após, descreve-se na Tabela 3 os indicadores e construtos de acessibilidade.

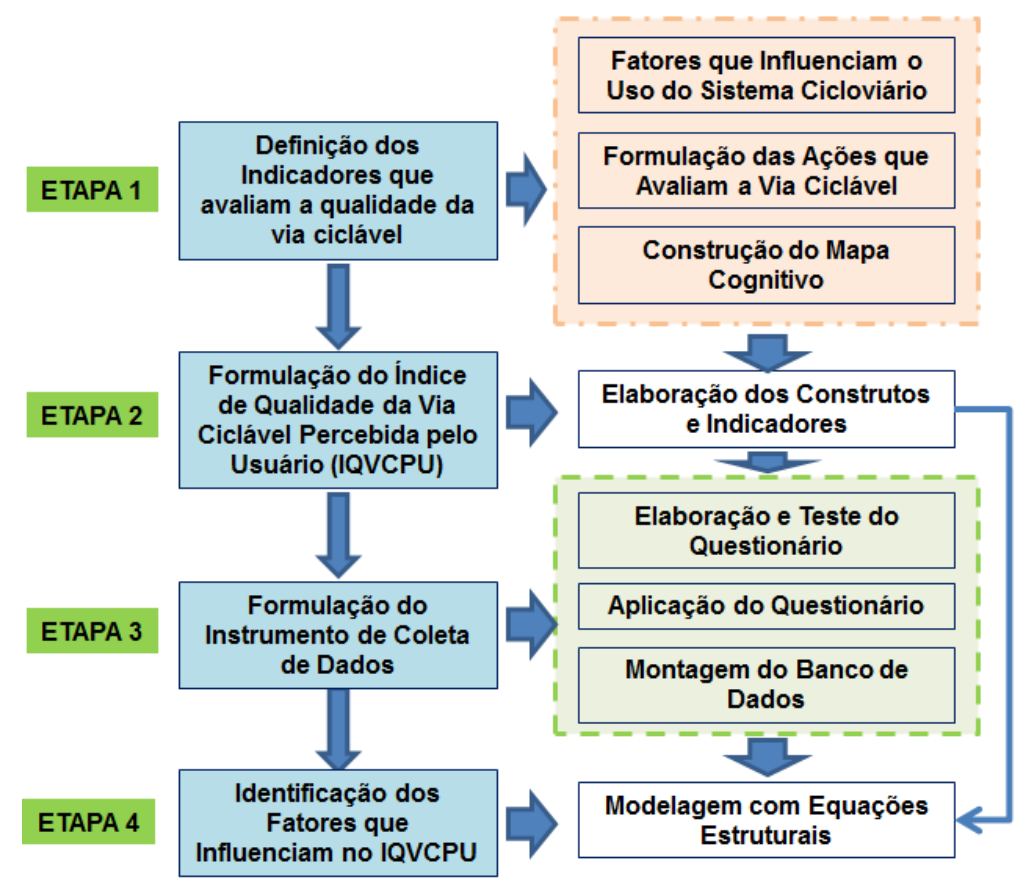

Figura 2 - Método para construção do IQVCPU e dos fatores que influenciam na qualidade percebida: definição dos indicadores que avaliam a qualidade da via ciclável, formulação de qualidade da via ciclável percebida pelo usuário, formulação do instrumento de coleta de dados, identificação dos fatores que influenciam no IQVCPU. Adaptado de Romano (2017).

A Figura 2 ilustra as quatro etapas do método, que incluem a definição dos indicadores que avaliam a qualidade da via ciclável (etapa 1), a formulação do Índice de Qualidade da Via Ciclável percebida pelo usuário (etapa 2), a formulação do instrumento da coleta de dados (etapa 3), a identificação dos fatores que influenciam no IQVCP (etapa 4) e suas respectivas subetapas. 
Tabela 1 - Fatores de viagem e ambientais relacionados ao sistema cicloviário

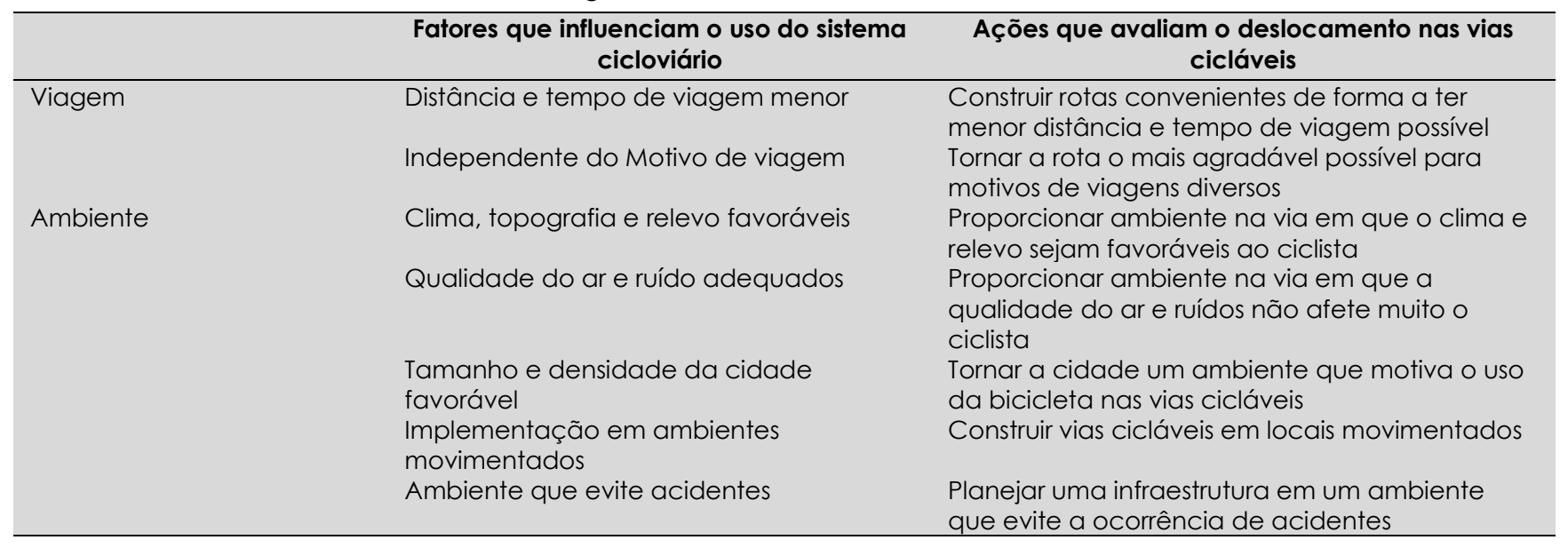

Nota: A Tabela apresenta um exemplo da transformação de dois fatores (viagem e ambiente), dos 31 fatores que influenciam o uso do sistema cicloviário, em ações que avaliam as vias cicláveis. Viagem e ambiente: fatores que influenciam o uso do sistema cicloviário e ações que avaliam o deslocamento nas vias cicláveis. Fonte: Romano (2017).

Tabela 2 - Indicadores cognitivos de relação meios e fins

\begin{tabular}{|c|c|c|c|}
\hline & Fins & Meios & \\
\hline \multirow{20}{*}{$\begin{array}{l}\text { Qualidade } \\
\text { das Vias } \\
\text { Analisadas } \\
\text { Cicláveis }\end{array}$} & \multirow{2}{*}{$\begin{array}{l}\text { (1) Tornar o ambiente } \\
\text { agradável e } \\
\text { confortável para o } \\
\text { ciclismo }\end{array}$} & $\begin{array}{l}\text { Tornar a sensação da viagem a } \\
\text { mais agradável possível }\end{array}$ & $\begin{array}{l}\text { Proporcionar ambiente na via em que o clima e relevo sejam } \\
\text { favoráveis ao ciclista }\end{array}$ \\
\hline & & $\begin{array}{l}\text { Oferecer menor risco à saúde } \\
\text { do ciclista }\end{array}$ & $\begin{array}{l}\text { Proporcionar ambiente na via em que a qualidade do ar e } \\
\text { dos ruídos não afete muito o ciclista }\end{array}$ \\
\hline & \multirow{6}{*}{$\begin{array}{l}\text { (2) Promover } \\
\text { segurança na } \\
\text { infraestrutura }\end{array}$} & \multirow{2}{*}{$\begin{array}{l}\text { Proporcionar uma operação } \\
\text { segura }\end{array}$} & Tornar a infraestrutura agradável ao uso \\
\hline & & & Construir a infraestrutura com características adequadas \\
\hline & & \multirow{2}{*}{$\begin{array}{l}\text { Oferecer ao ciclista uma } \\
\text { percepção de segurança }\end{array}$} & Diminuir o risco de assalto e roubos \\
\hline & & & Construir vias cicláveis em locais movimentados \\
\hline & & \multirow[t]{2}{*}{ Diminuir o número de acidentes } & Tomar medidas de segurança viária necessárias \\
\hline & & & $\begin{array}{l}\text { Planejar uma infraestrutura em um ambiente que evite a } \\
\text { ocorrência de acidentes }\end{array}$ \\
\hline & \multirow{2}{*}{$\begin{array}{l}\text { (3) Promover } \\
\text { segurança } \\
\text { envolvendo os modos } \\
\text { motorizados }\end{array}$} & Diminuir o número de acidentes & $\begin{array}{l}\text { Ter um tráfego próximo que não ofereça risco à vida do } \\
\text { ciclista }\end{array}$ \\
\hline & & $\begin{array}{l}\text { Melhorar o convívio entre } \\
\text { ciclista e os modos motorizados }\end{array}$ & $\begin{array}{l}\text { Dar ao usuário uma percepção segura em relação aos } \\
\text { modos motorizados }\end{array}$ \\
\hline & \multirow{2}{*}{$\begin{array}{l}\text { (4) Garantir que a } \\
\text { bicicleta possa } \\
\text { competir com os } \\
\text { outros modos } \\
\text { alternativos }\end{array}$} & $\begin{array}{l}\text { Tornar a cidade agradável } \\
\text { para viagens de curta e média } \\
\text { distância }\end{array}$ & $\begin{array}{l}\text { Tornar a cidade um ambiente que motiva o uso da bicicleta } \\
\text { nas vias cicláveis }\end{array}$ \\
\hline & & Ter custo de uso eficiente & $\begin{array}{l}\text { Oferecer benefícios à bicicleta na via aos comparados a } \\
\text { outros modos alternativos }\end{array}$ \\
\hline & \multirow[t]{3}{*}{$\begin{array}{l}\text { (5) Tornar a escolha } \\
\text { da bicicleta eficiente }\end{array}$} & \multirow[t]{2}{*}{$\begin{array}{l}\text { Promover menor tempo de } \\
\text { viagem no deslocamento }\end{array}$} & $\begin{array}{l}\text { Construir rotas convenientes de forma a ter menor distância } \\
\text { de viagem possível }\end{array}$ \\
\hline & & & Tornar a rota agradável para a velocidade necessária \\
\hline & & $\begin{array}{l}\text { Levar o usuário em segurança } \\
\text { até o seu destino }\end{array}$ & $\begin{array}{l}\text { Inserir a via cicloviária em lugares atrativos (origem e destino) } \\
\text { e que seja o mais contínua possível }\end{array}$ \\
\hline & \multirow[t]{4}{*}{$\begin{array}{l}\text { (6) Tornar a bicicleta } \\
\text { acessível à maior } \\
\text { parte da população }\end{array}$} & $\begin{array}{l}\text { Oferecer acessibilidade na via } \\
\text { ciclável independente de } \\
\text { qualquer característica } \\
\text { individual }\end{array}$ & \\
\hline & & $\begin{array}{l}\text { Criar cultura e políticas de } \\
\text { mobilidade sustentável }\end{array}$ & $\begin{array}{l}\text { Incentivar o uso da bicicleta para viagens utilitárias pela } \\
\text { sociedade }\end{array}$ \\
\hline & & Diminuir os gastos do ciclista & $\begin{array}{l}\text { Ter custo bem acessível ao se usar a bicicleta nas vias } \\
\text { cicláveis }\end{array}$ \\
\hline & & $\begin{array}{l}\text { Usar a rota para realizar viagens } \\
\text { para qualquer atividade }\end{array}$ & $\begin{array}{l}\text { Tornar a rota o mais agradável possível para motivos de } \\
\text { viagens diversos }\end{array}$ \\
\hline & $\begin{array}{l}\text { (7) Tornar a } \\
\text { percepção do usuário } \\
\text { agradável em } \\
\text { relação à via ciclável }\end{array}$ & $\begin{array}{l}\text { Tornar a via confortável ao uso } \\
\text { trazendo satisfação pessoal }\end{array}$ & $\begin{array}{l}\text { Oferecer ao usuário uma percepção agradável da via } \\
\text { ciclável }\end{array}$ \\
\hline
\end{tabular}

Nota: Indicadores cognitivos de relação meios e fins. Qualidade das vias analisadas cicláveis, cujos fins são promover segurança, envolvendo os modos motorizados, garantir a participação da bicicleta no ambiente do trânsito, tornar a escolha de uso da bicicleta eficiente, acessível à população e tornar a percepção do usuário em relação à via ciclável agradável; e 
os meios são para proporcionar: clima e relevo favoráveis, qualidade do ar, infraestrutura adequada e agradável, segurança pública e segurança viária, viagens utilitárias, custo acessível, rota agradável e rotas acessíveis e, por fim, percepção agradável da via ciclável. Fonte: adaptado do Mapa Cognitivo de Romano (2017).

Tabela 3 - Indicadores e Construtos

\begin{tabular}{|c|c|c|}
\hline Construto & Sigla & Indicador \\
\hline \multirow[t]{17}{*}{ Acessibilidade } & Acessl & Gênero \\
\hline & Acess2 & Idade \\
\hline & Acess3 & Escolaridade \\
\hline & Acess 4 & Ocupação \\
\hline & Acess 5 & Renda \\
\hline & Acess6 & Responsabilidades familiares \\
\hline & Acess7 & Motivo da viagem \\
\hline & Acess8 & Flexibilidade de horário \\
\hline & Acess9 & Condição física \\
\hline & Acess 10 & Experiência com ciclismo (Habilidade) \\
\hline & Acessl 1 & Custo de aquisição da bicicleta \\
\hline & Acess 12 & Custo de estacionamento (bicicletário) \\
\hline & Acess 13 & Custo de manutenção da bicicleta \\
\hline & Acess 14 & Hábito \\
\hline & Acess 15 & Questões relacionadas à saúde \\
\hline & Acessl6 & Política de mobilidade sustentável (governo) \\
\hline & Acessl7 & Cultura de mobilidade sustentável (sociedade) \\
\hline \multirow{4}{*}{$\begin{array}{l}\text { Avaliação dos modos } \\
\text { alternativos }\end{array}$} & Amal & Custos generalizados dos modos de transporte motorizado \\
\hline & Ama2 & Distância da viagem comparada com outros modos de transporte \\
\hline & Ama3 & Tamanho da cidade (cidade de pequeno, médio ou grande porte) \\
\hline & Ama4 & Densidade da cidade \\
\hline \multirow[t]{9}{*}{ Ambiente } & Ambl & Características meteorológicas (Precipitação) \\
\hline & Amb2 & Temperaturas médias \\
\hline & Amb3 & Umidade relativa do ar \\
\hline & Amb4 & Vegetação ao longo da rota \\
\hline & Amb5 & Cobertura arbórea (sombra) \\
\hline & Amb6 & Características topográficas \\
\hline & Amb7 & Ambiente íngreme (subida e descida) ou plano \\
\hline & Amb8 & Polvição atmosférica \\
\hline & Amb9 & Polvição sonora \\
\hline \multirow[t]{10}{*}{ Eficiência } & Efil & Distância de viagem \\
\hline & Efi2 & Tempo de viagem \\
\hline & Efi3 & Horário da viagem \\
\hline & Efi4 & Velocidade da bicicleta \\
\hline & Efi5 & Inserir a via cicloviária em polos geradores de viagens (origem e destino) \\
\hline & Efi6 & Existência de polos atrativos ao longo da via cicloviária \\
\hline & Efi7 & Continuidades da infraestrutura \\
\hline & Efi8 & Preferência nos cruzamentos \\
\hline & Efi9 & Existência de facilidades no destino (chuveiro, armário, estacionamento) \\
\hline & Efilo & Segregação com os pedestres \\
\hline \multirow[t]{5}{*}{ Percepção do usuário } & Pul & Satisfação pessoal (valores pessoais) \\
\hline & Pu2 & Uso de bicicleta atrativo \\
\hline & Pu3 & Paisagem atraente \\
\hline & Pu4 & Conforto \\
\hline & Pu5 & Vandalismo (pichação, iluminação quebrada) - Poluição visual \\
\hline \multirow{19}{*}{$\begin{array}{l}\text { Segurança na } \\
\text { infraestrutura }\end{array}$} & Seginfr 1 & Tipo de uso do solo (residências, comércio, indústrias, escola, universidade) \\
\hline & Seginfr2 & Padrão da vegetação (segurança) \\
\hline & Seginfr3 & lluminação \\
\hline & Seginfr4 & Risco de roubos e assaltos na região \\
\hline & Seginfr5 & Tipo de via (ciclovia, ciclofaixa, ciclorrota ou espaço compartilhado) \\
\hline & Seginfr6 & Largura \\
\hline & Seginfr7 & Número de faixas \\
\hline & Seginfr8 & Sinalização vertical \\
\hline & Seginfr9 & Sinalização horizontal \\
\hline & Seginfr 10 & Estado de conservação das vias \\
\hline & Seginfr 11 & Estado de conservação da sinalização \\
\hline & Seginfr 12 & Periodicidade da manutenção \\
\hline & Seginfr 13 & Existência de objetos estacionários \\
\hline & Seginfr 14 & Detritos na rota \\
\hline & Seginfr 15 & Defeitos na superfície \\
\hline & Seginfr 16 & Acúmulo de água parada (poças) \\
\hline & Seginfr 17 & Risco de derrapagens e quedas \\
\hline & Seginfr 18 & Número de colisões com pedestres ou outros ciclistas \\
\hline & Seginfr19 & Existência de pontes com calçada estreita \\
\hline
\end{tabular}


Tabela 3 - Indicadores e Construtos

(conclusão)

\begin{tabular}{lll}
\hline Construto & Sigla & Indicador \\
\hline Segurança envolvendo & Segmot1 & Número de colisões com veículos motorizados (Acidentes na via motorizada) \\
os motorizados & Segmot2 & Velocidade do tráfego \\
& Segmot3 & Volume do tráfego \\
& Segmot4 & Composição do tráfego \\
& Segmot5 & Classificação funcional do tráfego \\
& Segmot6 & Pontos de parada devido a intersecções com os modos motorizados \\
& Segmot7 & Número de cruzamentos entre a via e o tráfego motorizado \\
& Segmot8 & Cruzamentos com modos motorizados em rotatória \\
& Segmot9 & Comportamento dos motoristas perto das bicicletas \\
& Segmot10 & Proximidade de veículos motorizados \\
& Segmot11 & Direito de passagem na via motorizada \\
& Segmot12 & Portas dos veículos motorizadas abertas \\
& Segmot13 & Percepção da bicicleta pelo motorista nas curvas \\
& Usol & Uso nos próximos dias \\
& Uso2 & Uso no futuro \\
Uso3 & Intenção de uso no futuro \\
Uso & Tirar proveito das vias \\
& Uso5 & Utilizar sempre que disponível \\
& Uso6 & Úteis para uso de bicicleta \\
& Uso7 & Adequadas para uso da bicicleta \\
Uso8 & Ajustar a rota \\
\hline
\end{tabular}

Nota: Tabela trata dos construtos e indicadores de acessibilidade, avaliação dos modos alternativos, ambiente, eficiência, percepção do usuário e segurança na infraestrutura. Acess - Acessibilidade; Ama - Avaliação dos modos alternativos; Amb Ambiente; Efi - Eficiência; Pu - Percepção do usuário; Seginfr - Segurança na infraestrutura; Semot - Segurança envolvendo os motorizados. Fonte: Indicadores e Construtos da percepção da via ciclável construídos a partir da revisão da literatura pelos autores do artigo.

O instrumento de pesquisa possui 85 afirmações, que refletem os 77 indicadores relacionados aos 7 construtos mencionados anteriormente. 0 questionário está dividido em 8 partes, além das questões para caracterização da amostra, tais como dados socioeconômicos. 0 questionário foi elaborado no Google Forms e foi distribuído em Brasília - DF, pelas redes sociais, no período de 23/10 a 15/11 de 2017, entre usuários de bicicleta (própria e compartilhada) residentes no Distrito Federal. 0 tamanho da amostra foi calculado utilizando-se o software G-Power ${ }^{2}$, com efeito de força $\left(\mathrm{f}^{2}\right)$ mediano $(0,15)$, significância (p-value) de 0,05 e nível de poder estatístico de 0,80 . Deve-se avaliar o construto que recebe o maior número de setas ou tem o maior número de preditores; assim o construto "Uso" recebe 7 setas no modelo hipotético inicial (7 preditores) apresentado na Figura 4. A amostra mínima necessária seria de 103 respondentes, mas no total foram obtidas 108 respostas válidas para usuários de bicicleta (própria e compartilhada).

Na Etapa 2, identificaram-se os construtos e indicadores de cada categoria, representados pelo mapa cognitivo (Tabela 2). Nela observam-se os grupos de conceitos que representam os construtos. Assim, por exemplo, "Tornar o ambiente agradável e confortável para o ciclismo" (Fins 1) constitui o construto "Ambiente". Os conceitos em "Promover segurança na infraestrutura" (Fins 2) formam o construto "Segurança 1"; "Promover a segurança envolvendo os modos motorizados" (Fins 3) é a "Segurança 2"; "Garantir que a bicicleta possa competir com os modos alternativos" (Fins 4) é a "Avaliação dos modos motorizados"; "Tornar a bicicleta acessível à maior parte da população" (Fins 5) é a "Acessibilidade"; "Tornar a escolha da bicicleta eficiente" (Fins 6) é a "Eficiência" e "Tornar a percepção do usuário em relação à via ciclável agradável" (Fins 7) é o construto "Percepção do usuário".

Assim, reuniram-se 7 construtos alimentados por 14 indicadores (Figura 3), como apresentado na Tabela 3, juntamente com o constructo "Uso".

\footnotetext{
${ }^{2}$ Software G-Power: utilizado para calcular o tamanho de efeito e tamanho da amostra por meio de opções gráficas.
} 


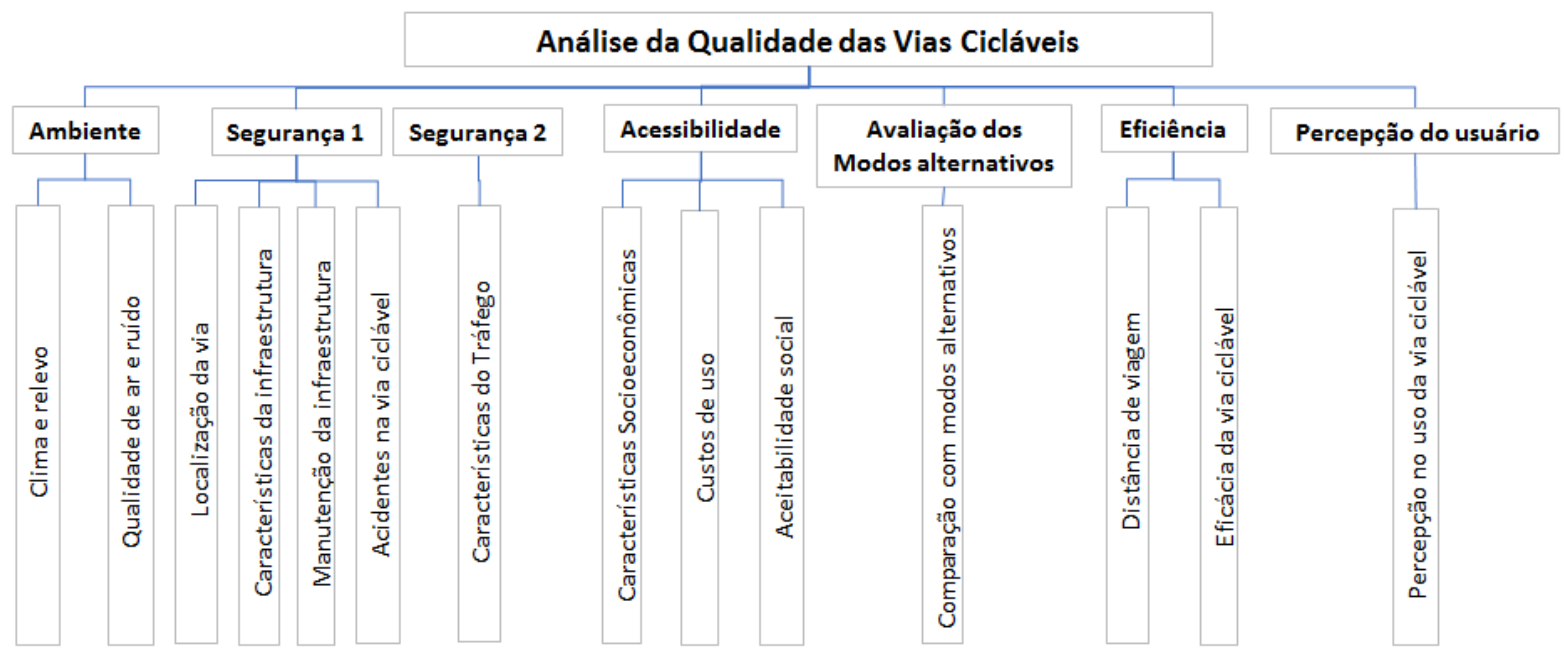

Figura 3 - Índice de Qualidade da Via Ciclável Percebida pelo Usuário. Fonte: Elaboração dos autores do artigo baseado em Largura (2012).

Desta forma o Índice de Qualidade da Via Ciclável Percebida pelo Usuário contempla as variáveis antecedentes ambiente, segurança 1 (infraestrutura cicloviária), segurança 2 (modos motorizados), acessibilidade, eficiência, avaliação dos modos alternativos e a variável consequente uso das vias cicláveis; tal Índice foi formulado como modelo hipotético para ser empiricamente testado. Desta feita, o modelo para explicar o uso das vias cicláveis baseado nos referidos indicadores segue na Figura 4.

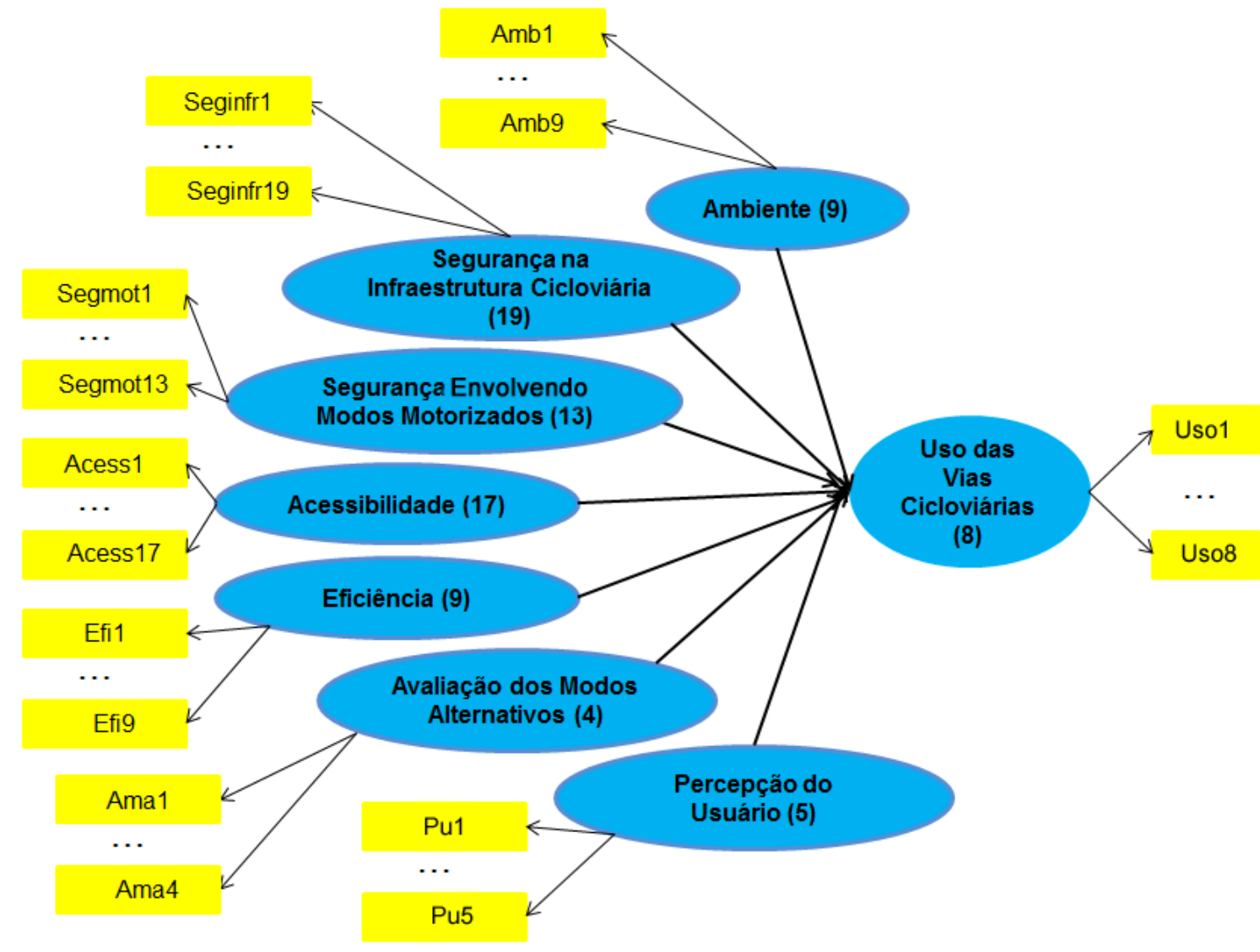

Figura 4 - Modelo hipotético inicial com as variáveis ambiente, segurança envolvendo infraestrutura cicloviária, segurança envolvendo modos motorizados, acessibilidade, eficiência, avaliação dos modos alternativos e a variável consequente uso das vias cicláveis. Nota: Acess - Acessibilidade; Ama - Avaliação dos modos alternativos; Amb - Ambiente; Efi - Eficiência; Pu Percepção do usuário; Seginfr - Segurança na infraestrutura; Semot - Segurança envolvendo os motorizados; Uso - Uso das Vias Cicláveis. Fonte: SMART PLS 3.0. 
Na Etapa 3, conforme cada construto, foram registradas afirmações para medir os indicadores de acordo com a escala likert de cinco pontos, para o entrevistado manifestar a concordância com a afirmação. A escala varia de 1 (discordo), 2 (discordo parcialmente), 3 (neutro), 4 (concordo parcialmente), 5 (concordo). Na Tabela 4, são apresentadas, como exemplo, as afirmações dos 9 indicadores do construto acessibilidade, avaliação dos modos alternativos, ambiente, eficiência, percepção do usuário e segurança na infraestrutura.

Tabela 4 - Indicadores e declarações do usuário da via ciclável

\begin{tabular}{|c|c|c|}
\hline & Indicador & Afirmação \\
\hline Ambl & $\begin{array}{l}\text { Características meteorológicas } \\
\text { (Precipitação) }\end{array}$ & Frequência de chuvas é favorável para o uso de bicicleta. \\
\hline Amb2 & Temperaturas médias & $\begin{array}{l}\text { Considero a temperatura ambiente adequada para o uso de } \\
\text { bicicleta. }\end{array}$ \\
\hline Amb3 & Umidade relativa do ar & $\begin{array}{l}\text { Considero a umidade relativa do ar adequada para o uso de } \\
\text { bicicleta. }\end{array}$ \\
\hline Amb4 & Vegetação ao longo da rota & $\begin{array}{l}\text { Na rota das vias cicloviárias, há vegetação ao longo das vias } \\
\text { (árvores, arbustos, grama). }\end{array}$ \\
\hline Amb5 & Cobertura arbórea (sombra) & $\begin{array}{l}\text { A cobertura arbórea é adequada para o uso de bicicleta } \\
\text { proporcionando sombra. }\end{array}$ \\
\hline Amb6 & Características topográficas & A topografia é favorável para o uso de bicicleta. \\
\hline Amb7 & $\begin{array}{l}\text { Ambiente íngreme (subida e descida) } \\
\text { ou plano }\end{array}$ & $\begin{array}{l}\text { Não há pontos na rota da via cicloviária que sejam muito } \\
\text { íngremes e que compliquem na subida ou na descida. }\end{array}$ \\
\hline Amb8 & Polvição atmosférica & A polvição atmosférica é adequada para a saúde do ciclista. \\
\hline Amb9 & Polvição sonora & A polvição sonora é adequada para a saúde do ciclista. \\
\hline
\end{tabular}

Nota: Indicadores e declarações do usuário da via ciclável. Tabela trata de um exemplo de afirmações mensuráveis para os Indicadores do construto Ambiente. Abreviação do indiciadores do construto Ambiente - Amb. Fonte: Autores do artigo.

Na Etapa 4, que compreende os Resultados da Modelagem com Equações Estruturais, foi definido um modelo para avaliar a qualidade das vias cicláveis que consiste na variável dependente ser o "Uso da Via Ciclável" (Figura 4). Na aplicação do modelo, as características dos respondentes evidenciaram que a maioria dos entrevistados são homens (68,52\%), possuem como principal atividade o trabalho $(67,59 \%)$, têm Pós-Graduação (42,59\%), idade bem distribuída acima de 18 anos (não houve entrevistados com menos de 18 anos), trabalham mais de 30 horas semanais $(56,48 \%)$, têm renda superior a 6 salários mínimos (77,78\%), são solteiros (52,78\%) e não têm filho(s) (62,04\%). É importante comentar que 24,07\% dos entrevistados disseram exercer sua atividade principal na Universidade de Brasília.

Dessa maneira, o modelo referido foi aplicado, incluindo-se os fatores ao contexto do DF, por meio da testagem das seguintes hipóteses: H1 - Quanto mais agradável o clima ao redor da infraestrutura maior a intenção de se usar a via ciclável; H2 - Quanto mais segura a infraestrutura maior a intenção de se usar a via ciclável; H3 - Quanto mais seguro o relacionamento entre a bicicleta e os modos motorizados, em pontos críticos da rota, maior a intenção de se usar a via ciclável; H4 - Quanto mais acessível é o uso da bicicleta nas vias cicláveis maior a intenção de se usar a via; H5 - Quanto mais eficiente o uso da bicicleta nas vias cicláveis maior a intenção de se usar a via; H6 - Quanto melhor a avaliação da bicicleta com os modos alternativos maior a intenção de se usar a via ciclável; e H7 - Quanto melhor a percepção em relação à via ciclável maior a intenção de se usar a via.

A partir do modelo referido (Figura 4), testou-se a confiabilidade de itens de todos os fatores (Aceitabilidade Social, Acessibilidade, Atratividade da rota, Avaliação de modos alternativos, Características da via motorizada adequada, Características do Usuário, Clima agradável, Eficiência no percurso, Intersecção com modos motorizados adequada, Qualidade da via ciclável percebida, Relevo e Topografia adequada, Segurança na infraestrutura, Segurança na infraestrutura e Uso). Foram consideradas as cargas 
fatoriais dos itens maior ou igual a 0,6 (Hair et al., 2005), como ilustrado na Figura 5. Ao todo, 13 indicadores que apresentaram baixa carga fatorial foram excluídos.

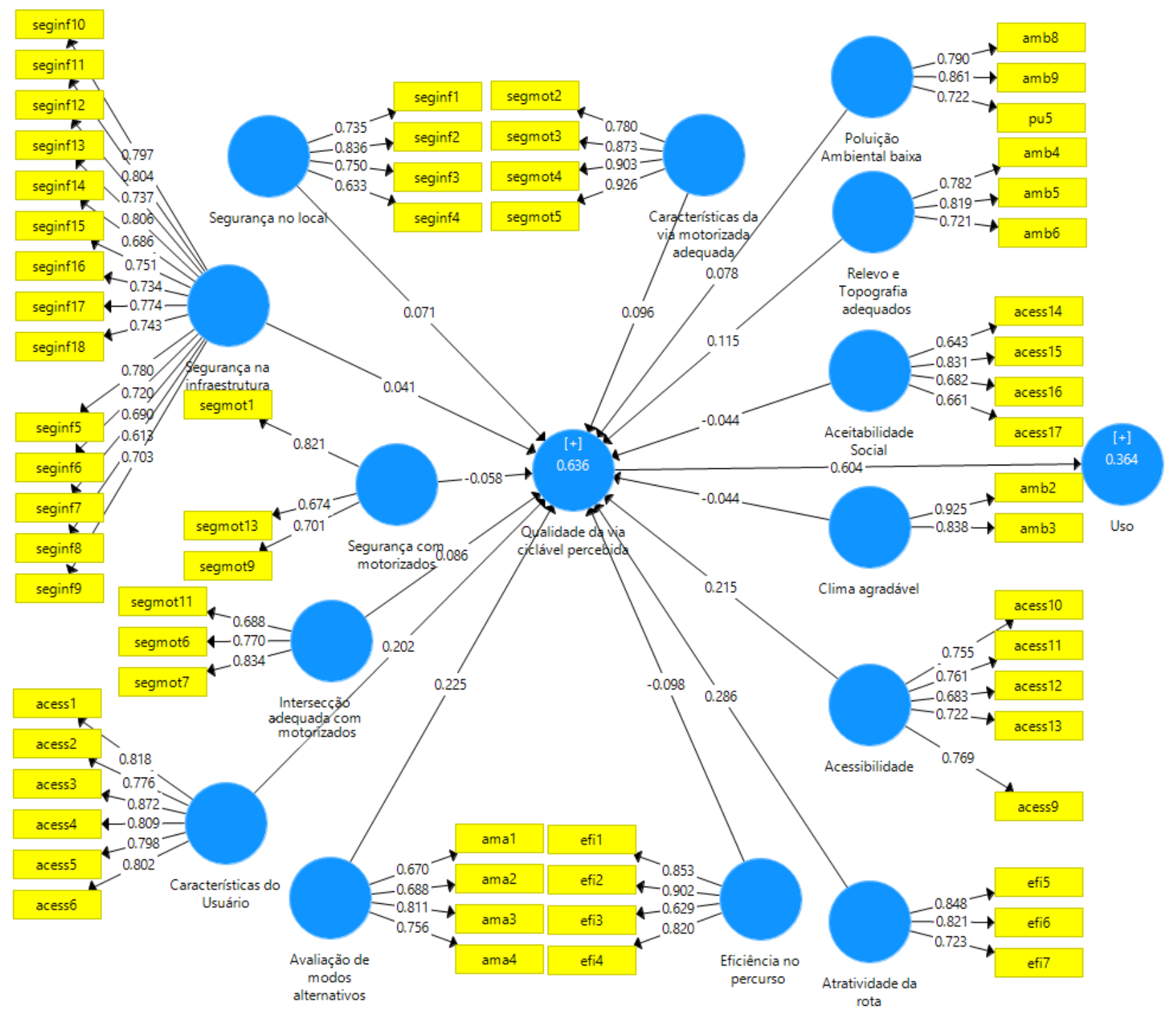

Figura 5 - Modelo do índice de Análise de Qualidade das Vias Cicláveis, após confiabilidade de item. Aceitabilidade Social (AS), Acessibilidade (A), Atratividade da rota (AR), Avaliação de modos alternativos (AMA), Características da via motorizada adequada (CVMA), Características do Usuário (CU), Clima agradável (CA), Eficiência no percurso (EP), Intersecção adequada com motorizados (IAM), Polvição Ambiental baixa (PAB) Qualidade da via ciclável percebida (QVCP), Relevo e Topografia adequados (RTA), Segurança na infraestrutura (SI), Segurança na infraestrutura (SI) e Uso. Nota: Nota: Acess - Acessibilidade; Ama - Avaliação dos modos alternativos; Amb - Ambiente; Efi - Eficiência; Pu - Percepção do usuário; Seginfr - Segurança na infraestrutura; Semot - Segurança envolvendo os motorizados; Uso - Uso das Vias Cicláveis. Fonte: SMART PLS 3.0.

\section{Análise e discussão dos resultados}

Após a análise de Confiabilidade dos itens, fez-se a análise da Confiabilidade Composta (CC), da Variação Média Extraída (AVE) e da Validez Interna (VIF) e todos os dados analisados mostraram que os indicadores de variáveis da via ciclável não se correlacionam com os indicadores de outras variáveis. 0 teste da Validez Interna com valores maiores que 10 apresenta problemas de multicolinearidade e a análise da Validade Discriminante (VD) deve apontar a validade discriminante superior às demais correlações para se discernir a convergência entre os construtos (Ramírez et al., 2014; Mariano et al., 2017; Romano, 2017). 
Os resultados das análises mostram-se satisfatórios para os parâmetros estabelecidos para a testagem do modelo, como pode ser observado na Tabela 5 e na Tabela 6.

Tabela 5 - Coeficientes de validação do modelo: Confiabilidade Composta, AVE, VIF

\begin{tabular}{llll}
\hline Variável Latente (Constructo) & CC & AVE & VIF \\
\hline Aceitabilidade Social (AS) & 0,799 & 0,502 & 1,358 \\
Acessibilidade (A) & 0,857 & 0,546 & 1,604 \\
Atratividade da rota (AR) & 0,841 & 0,638 & 1,784 \\
Avaliação de modos alternativos (AMA) & 0,822 & 0,538 & 1,440 \\
Características da via motorizada adequada (CVMA) & 0,927 & 0,761 & 1,961 \\
Características do Usuário (CU) & 0,921 & 0,661 & 1,360 \\
Clima agradável (CA) & 0,875 & 0,779 & 1,654 \\
Eficiência no percurso (EP) & 0,881 & 0,652 & 1,843 \\
Intersecção adequada com motorizados (IAM) & 0,809 & 0,587 & 1,953 \\
Poluição Ambiental baixa (PAB) & 0,835 & 0,629 & 1,728 \\
Qualidade da via ciclável percebida (QVCP) & 0,894 & 0,628 & - \\
Relevo e Topografia adequados (RTA) & 0,819 & 0,601 & 1,676 \\
Segurança com motorizados (SM) & 0,778 & 0,54 & 1,425 \\
Segurança na infraestrutura (SI) & 0,944 & 0,548 & 2,692 \\
Segurança no local (SL) & 0,829 & 0,551 & 2,889 \\
Uso & 0,917 & 0,689 & - \\
\hline
\end{tabular}

Nota: Abreviação dos coeficientes de validação do modelo: Confiabilidade Composta (CC); Variação Média extraída (AVE); Validez Interna (VIF). Fonte: Extraído do software SmartPLS (v.3.2.7). 
Índice de Qualidade de Via Ciclável Percebido pelo Usuário (IQVCPU) em Brasília DF - Brasil

Tabela 6 - Análise da Validade discriminante

\begin{tabular}{|c|c|c|c|c|c|c|c|c|c|c|c|c|c|c|c|c|}
\hline Variáveis & AS & A & AR & AMA & CVMA & CU & CA & EP & IMA & PAB & QVCP & RTA & SM & SI & SL & Uso \\
\hline Aceitabilidade Social (AS) & 0,71 & & & & & & & & & & & & & & & \\
\hline Acessibilidade (A) & 0,237 & 0,739 & & & & & & & & & & & & & & \\
\hline Atratividade da rota (AR) & 0,34 & 0,235 & 0,799 & & & & & & & & & & & & & \\
\hline Avaliação de modos alternativos (AMA) & 0,235 & 0,357 & 0,264 & 0,733 & & & & & & & & & & & & \\
\hline Características da via motorizada adequada (CVMA) & 0,132 & 0,195 & 0,392 & 0,255 & 0,872 & & & & & & & & & & & \\
\hline Características do Usuário (CU) & 0,264 & 0,329 & 0,402 & 0,259 & 0,282 & 0,813 & & & & & & & & & & \\
\hline Clima agradável (CA) & 0,16 & 0,193 & 0,218 & 0,234 & 0,152 & 0,187 & 0,882 & & & & & & & & & \\
\hline Eficiência no percurso (EP) & 0,144 & 0,44 & 0,31 & 0,389 & 0,272 & 0,189 & 0,455 & 0,808 & & & & & & & & \\
\hline Intersecção adequada com motorizados (IAM) & 0,305 & 0,033 & 0,372 & 0,314 & 0,568 & 0,191 & 0,024 & 0,09 & 0,767 & & & & & & & \\
\hline Polvição Ambiental baixa (PAB) & 0,12 & 0,353 & 0,284 & 0,168 & 0,301 & 0,225 & 0,301 & 0,329 & 0,066 & 0,796 & & & & & & \\
\hline Qualidade da via ciclável percebida (QVCP) & 0,323 & 0,479 & 0,576 & 0,516 & 0,431 & 0,502 & 0,243 & 0,293 & 0,388 & 0,389 & 0,784 & & & & & \\
\hline Relevo e Topografia adequados (RTA) & 0,287 & 0,319 & 0,33 & 0,317 & 0,25 & 0,271 & 0,49 & 0,314 & 0,179 & 0,316 & 0,495 & 0,776 & & & & \\
\hline Segurança com motorizados (SM) & 0,151 & 0,045 & 0,359 & 0,096 & 0,401 & 0,196 & 0,11 & 0,073 & 0,389 & 0,297 & 0,244 & 0,153 & 0,732 & & & \\
\hline Segurança na infraestrutura (SI) & 0,332 & 0,288 & 0,504 & 0,212 & 0,505 & 0,304 & 0,101 & 0,199 & 0,411 & 0,462 & 0,522 & 0,369 & 0,365 & 0,74 & & \\
\hline Segurança no local (SL) & 0,365 & 0,327 & 0,51 & 0,242 & 0,362 & 0,269 & 0,22 & 0,133 & 0,319 & 0,52 & 0,539 & 0,444 & 0,383 & 0,721 & 0,744 & \\
\hline Uso & 0,107 & 0,337 & 0,257 & 0,367 & 0,276 & 0,331 & 0,254 & 0,239 & 0,22 & 0,229 & 0,62 & 0,314 & 0,008 & 0,192 & 0,307 & 0,831 \\
\hline
\end{tabular}

Fonte: Extraído do software SmartPLS (v.3.2.7). 
A análise do Coeficiente de Caminhos $(\beta)$ e do $\mathrm{R}^{2}$ evidenciou que as variáveis latentes Atratividade da Rota (AR com $\beta=0,286$ ), Avaliação dos modos alternativos (AMA com $\beta=0,225$ ), Acessibilidade (A com $\beta=0,215$ ) e Características do Usuário (CU com $\beta=0,202$ ) mostram o impacto sobre a Qualidade de Via Ciclável Percebida (QVCP com $\left.R^{2}=0,636\right)$, enquanto esta tem impacto sobre o Uso da via ciclável $\left(R^{2}=0,604\right)$. $\mathrm{Na}$ análise Bootstrapping, foi possível determinar que somente os construtos Atratividade da Rota, Avaliação dos modos alternativos, Acessibilidade e Características do Usuário possuem significância na análise da variável dependente QVCP, significantes a $1 \%$ no teste $t$-student, isto é, os valores da estatística $t$ são maiores que 2,576. Já em relação ao Uso, o IQVCPU apresentou também significância de 1\%. Os demais construtos não apresentaram significância considerável.

$\mathrm{Na}$ análise, os referidos indicadores foram aqueles que apresentaram as piores avaliações, segundo a percepção dos ciclistas. Em relação às hipóteses confirmadas pelo modelo, já era esperado que a Atratividade da Rota, que explicou a qualidade da via ciclável em até 16,82\%, apresentasse significância, tal como foram identificados por Yang et al. (2019) e Buehler \& Pucher (2012). A principal crítica feita pelos ciclistas, referente à configuração da via, é porque ela não é contínua, o que ocasiona a falta de interligação adequada, fazendo com que o ciclista tenha que compartilhar a via com outros modos motorizados em alguns trechos. Isso demonstra falta de planejamento adequado da infraestrutura das ciclovias que condiciona as preferências dos diferentes usuários pela escolha da via, como identificado nos estudos de alguns pesquisadores (Winters et al. 2011; Segadilha \& Sanches, 2012; Chantaway et al., 2014; Terch \& Cao, 2018).

A Avaliação dos modos alternativos explica em 11,07\% o IQVCPU e torna perceptível que a bicicleta só será capaz de ser uma opção mais aceitável pela sociedade, comparando com os demais modos, se houver uma infraestrutura segura que auxilie no deslocamento, como foi verificado por Terch \& Cao (2018). Para a Acessibilidade $(10,41 \%)$ e Características do Usuário (10,52\%), os usuários identificaram que a qualidade da via ciclável influencia a atenção visual do ciclista, facilitando seu uso como também foi observado no estudo de Vansteenkiste et al. (2017).

Sousa (2012) menciona que as pessoas mais idosas, geralmente, não dispõem de capacidade física para pedalar e as mulheres estão mais sujeitas aos riscos sociais, porém uma via sem barreiras e segura é mais acessível à maioria dos indivíduos. Finalmente foi identificado que o Índice de Qualidade da Via Ciclável Percebida (IQVCP) pelo usuário explica o seu uso em até 36,48\%, o que é perceptivo já que qualquer deficiência que a via apresentar, para o incentivo do uso da bicicleta, desestimula o seu uso.

\section{Conclusões e considerações}

O objetivo deste trabalho foi desenvolver um Índice de Qualidade da Via Ciclável Percebida pelo Usuário (IQVPU) e avaliar os fatores que influenciam na percepção da qualidade para o deslocamento nas vias cicláveis implantadas em Brasília-DF, utilizando-se modelagem de equações estruturais. Dessa maneira, o referido objetivo foi alcançado a partir da compreensão da percepção de qualidade que os usuários têm da bicicleta sobre as vias. No começo do desenvolvimento do estudo foi necessário realizar uma análise para transformar os fatores que influenciam o uso da bicicleta, observados na Revisão Bibliográfica, em variáveis latentes que pudessem avaliar a qualidade das vias. Essas variáveis foram usadas como entrada no modelo inicial para auxiliar no desenvolvimento do questionário aplicado. Os referidos fatores foram aplicados ao contexto do Distrito Federal por meio da testagem das hipóteses descritas na sessão do método.

Com o resultado da coleta dos dados foi possível, através de análise exploratória, realizar a modelagem de equações estruturais para o desenvolvimento do Modelo do IQVPV; porém, por meio da análise exploratória, foi possível definir 16 construtos, sendo que somente 14 mostraram-se como variáveis independentes, uma como variável dependente e uma sendo variável independente e dependente. No entanto, após finalizar a modelagem, 10 dessas variáveis latentes não apresentaram significância considerável para ter impacto sobre a qualidade da via ciclável percebida, o que não era esperado, principalmente no que se refere aos construtos que refletem questões da via motorizada e da infraestrutura. 
Os três construtos que avaliam o impacto dos motorizados sobre a qualidade da via ciclável (características da via motorizada adequada, intersecção adequada com modos motorizados e segurança com motorizados) foram os que obtiveram as três piores médias ao se analisar suas notas. Isso mostra a percepção negativa que os usuários de bicicleta têm em relação ao convívio com os modos motorizados.

O construto Segurança na Infraestrutura apresentou vários indicadores; entretanto nem todos os indicadores apresentaram significância na análise da qualidade da via, bem como o construto de Segurança no Local. Uma observação relativa à modelagem diz respeito a dois indicadores, referentes a Facilidades no Destino e à Segregação com os Pedestres, que representam algumas das principais questões apontadas pelos ciclistas, que não foram operacionalizáveis, e por isso foram retiradas da análise. Indica-se esse aspecto como uma limitação da pesquisa realizada.

Uma das contribuições produzidas por este estudo é o resultado que aponta os fatores representados pelo IQVPV e que os usuários mais relacionam com a qualidade da via ciclável. Tais fatores foram capazes de auxiliar o poder público no processo de decisão a respeito da necessidade de melhoria da infraestrutura cicloviária, promovendo o uso seguro da bicicleta como modo de transporte em áreas urbanas. Ainda, o estudo apresenta uma pesquisa inicial sobre a qualidade das vias cicláveis, com a percepção dos usuários para auxiliar na tomada de decisão de planejadores urbanos e de transportes, servindo de caminho a ser trilhado por pesquisadores na área de transporte.

\section{Agradecimentos}

Agradecemos ao CNPQ (Conselho Nacional de Desenvolvimeneto Científico e Tecnológico) pelo apoio financeiro do projeto de PIBIQ que possibilitou o estudo do Índice de Qualidade de Via Ciclável Percebido pelo Usuário (IQVCPU) em Brasília DF, e ao Grupo Comportamento, Transportes e Novas TecnologiasGCTNT-PPGT, UnB pelo apoio, desenvolvimento e conclusão dessa pesquisa.

\section{Referências}

Brasil (2009, 31 de agosto). Lei n. 4.397, de 27 de agosto de 2009. Dispõe sobre a criação do Sistema Cicloviário no âmbito do Distrito Federal e dá outras providências. Brasília: Diário Oficial do Distrito Federal, seção 1.

Brasil (2011, 29 de agosto). Decreto no 33.158, de 26 de agosto de 2011. Regulamenta a Lei no 3.639, de 28 de julho de 2005, Lei no 3.721, de 19 de dezembro de 2005, Lei no 3.885, de 7 de julho de 2006, Lei no 4.030, de 16 de outubro de 2007, Lei no 4.216, de 6 de outubro de 2008, Lei no 4.397, de 27 de agosto de 2009, e institui o Comitê Gestor da Política de Mobilidade Urbana por Bicicletas no Distrito Federal. Brasília: Diário Oficial do Distrito Federal, seção 1.

Buehler, R., \& Pucher, J. (2012). Cycling to work in 90 large American cities: new evidence on the role of bike paths and lanes. Transportation, 39, 409-432. https://doi.org/10.1007/s11116-011-9355-8

Calvey, J. C., Shackleton, J. P., Taylor, M. D., \& Llewellyn, R. (2015). Engineering condition assessment of cycling infrastructure: Cyclists' perceptions of satisfaction and comfort. Transportation Research Part A: Policy and Practice, 78, 134-143. doi: https://doi.org/10.1016/j.tra.2015.04.031

Campos, V. B. G., \& Cardoso, P. D. B. (2016). Metodologia para planejamento de um de sistema cicloviário. Transportes, 24(4), 39. doi: https://doi.org/10.14295/transportes.v24i4.1158

Chapadeiro, F. C. (2011). Limites e potencialidades do planejamento cicloviário: um estudo sobre a participação cidadã (Dissertação de Mestrado em Transportes). Departamento de Engenharia Civil e Ambiental, Universidade de Brasília, Brasília.

Chataway, E. S., Kaplan, S., Nielsen, T. A. S., \& Prato, C. G. (2014). Safety perceptions and reported behavior related to cycling in mixed traffic: A comparison between Brisbane and Copenhagen. Transportation Research Part F: Traffic Psychology and Behaviour, 23, 32-43. doi: https://doi.org/10.1016/j.trf.2013.12.021

Davis, J. (1987). Bicycle Safety Evaluation (Tese). Auburn University, Auburn, Alabama, Estados Unidos. 
Distrito Federal. Comitê Gestor da Política de Mobilidade Urbana por Bicicleta. (2014). Plano de Mobilidade por Bicicleta do Distrito Federal. Recuperado em 1 de janeiro de 2020, de

https://www.agenciabrasilia.df.gov.br/images/agencia_brasilia/2014/05 Maio/Ciclovida.pdf

Distrito Federal. Secretaria de Transporte e Mobilidade - Semob. (2017) + +Bike. Recuperado em 1 de janeiro de 2019, de http://www.semob.df.gov.br/bike/

Distrito Federal. Companhia do Metropolitano do Distrito Federal - Metrô-DF. (2018a). Plano de Desenvolvimento do Transporte Público sobre Trilhos do Distrito Federal - PDTT/DF - Relatório Final. Recuperado em 20 de maio de 2019, de http://www.metro.df.gov.br/?page_id=40044.

Distrito Federal. Companhia de Planejamento do Distrito Federal - Codeplan. (2018b). Pesquisa Distrital por Amostra de Domicílios do Distrito Federal - PDADDF. Recuperado em 12 de maio de 2020, de http://www.codeplan.df.gov.br/wpcontent/uploads/2019/03/PDAD_DF-Grupo-de-Renda-compactado.pdf

Distrito Federal. Departamento de Trânsito do Distrito Federal - Detran-DF. (2020). Evolução dos Acidentes de Trânsito com Morte no DF (Junho/2020). Recuperado em 30 de julho de 2020, de http://www.detran.df.gov.br/wpcontent/uploads/2018/06/df_serie_historica_fatal_2000_2020_junho.pdf

Du, M., Cheng, L., Li, X., \& Yang, J. (2020). Factors affecting the travel mode choice of the urban elderly in healthcare activity: comparison between core area and suburban area. Sustainable Cities and Society, 52, 101868.

https://doi.org/10.1016/j.scs.2019.101868

Epperson, B. (1994). Evaluating Suitability of Roadways for Bicycle Use: Toward a Cycling Level-of-Service Standard. Transportation Research Board, 1438, 9-16. Recuperado em 15, junho de 2017 em http://onlinepubs.trb.org/Onlinepubs/trr/1994/1438/1438-002.pdf.

Feitosa, Z. O. (2017). Modelo das motivações conscientes e não conscientes do uso do automóvel com base na Teoria do Comportamento Planejado (Tese de doutorado em Transportes). Departamento de Engenharia Civil e Ambiental, Universidade de Brasília, Brasília.

Ferreira, C. R. (2007). Análise de parâmetros que afetam a avaliação subjetiva de pavimentos cicloviários: um estudo de caso em ciclovias do Distrito Federal (Dissertação de Mestrado em Transportes). Departamento de Engenharia Civil e Ambiental, Universidade de Brasília, Brasília.

Gutiérrez, A. I., \& Reyes, M. L. (2017). Mujeres entre la libertad y la obligación. Prácticas de movilidad cotidiana en el Gran Buenos Aires. Revista Transporte y Territorio, 16, 147-166. doi: https://doi.org/10.34096/rtt.i16.3607

Hair, J. F., Black, W. C., Babin, B. J., Anderson, R. E., \& Tatham, R. L. (2005). Análise Multivariada de Dados (5. edição). Porto Alegre: Bookman

Kelarestaghi, K. B., Ermagun, A., \& Heaslip, K. P. (2019). Cycling usage and frequency determinants in college campuses. Cities, 90, 216-228. doi: https://doi.org/10.1016/j.cities.2019.02.004

Landis, B. W., Vattikuti, V. R., \& Brannick, M. T. (1997). Real-Time Human Perceptions: Toward a Bicycle Level of Service. Transportation Research Record: Journal of the Transportation Research Board, 1578(1), 119-126. doi: https://doi.org/10.3141/1578-15

Largura, A. E. (2012). Fatores que influenciam o uso de bicicleta em cidades de médio porte: estudo de caso em Balneário Camboriú/SC (Dissertação de Mestrado). Curso de Pós-Graduação em Arquitetura e Urbanismo, Universidade Federal de Santa Catarina, Santa Catarina.

Leiva, G. de C., \& Barbosa, H. M. (2006). Rota de ciclistas: um instrumento para o desenvolvimento urbano sustentável. Revista dos Transportes Públicos - ANTP, Ano 28, 65-82. Recuperado em 16 de junho de 2017 em http://filesserver.antp.org.br/_5dotSystem/download/dcmDocument/2013/01/10/8B542CA4-42C4-4770-8095FA1BC55E6EAD.pdf

Lourenço, U. (2015). Mobilidade saudável - análise da ciclovia na asa norte (W4/W5). Recuperado em 12 de março de 2019 , de https://www.mobilize.org.br/midias/pesquisas/textos-criticos-sobre-a-ciclovia-da-asa-norte-df.pdf

Mariano, A. M., Paldês, R. Á., Neumann, C., \& Nogueira, S. (2017). Fatores que influenciam as mulheres no consumo de moda online: Um estudo por meio das equações estruturais. Qualitas Revista Eletrônica, 18(1), 33-51.

https://doi.org/http://dx.doi.org/10.18391/req.v18i1.3656 
Mota, J. C., Sá, F. M. e, Isidoro, C., \& Pereira, B. C. (2019). Bike-Friendly Campus, new paths towards sustainable development. In U. M. de M. Azeiteiro, \& J. P. Davim (Eds.), Higher Education and Sustainability - Opportunities and

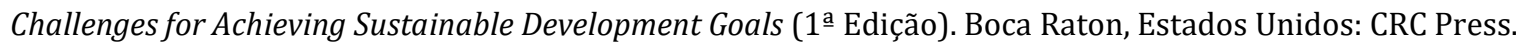

Pezzuto, C. C. (2002). Fatores que Influenciam o Uso da Bicicleta (Dissertação de Mestrado). Centro de Ciências Exatas e de Tecnologia, Universidade Federal de São Carlos, São Paulo.

Pucher, J., \& Buehler, R. (2017). Cycling towards a more sustainable transport future. Transport Reviews, 37(6), 689-694. doi: https://doi.org/10.1080/01441647.2017.1340234

Ramírez, P. E., Mariano, A. M., \& Salazar, E. A. (2014). Propuesta metodológica para aplicar modelos de ecuaciones estructurales con PLS: El caso del uso de las bases de datos científicas en estudiantes universitarios. Revista ADMpg - Gestão Estratégica, 7(2), 133-139. Recuperado em 25, fevereiro de 2018 em http://www.admpg.com.br/revista2014_2/Artigos/15\%20\%20-\%20Artigo_15.pdf

Romano, A. B. (2017). Avaliação dos Fatores que Influenciam na Qualidade do Deslocamento das Vias Cicláveis Implantadas em Brasília DF (Monografia de Projeto Final). Curso de Engenharia Civil. Faculdade de Tecnologia. Universidade de Brasília, Brasília.

San Francisco Department of Public Health. (2009). Bicycle Environmental Quality Index (BEQI). São Francisco, Estados Unidos: Program on Health, Equity and Sustainability, Environmental Health Section, San Francisco Department of Public Health. Recuperado em 16, junho de 2017, de https://merritt.cdlib.org/d/ark\%3A\%2F13030\%2Fm5qz3r51/1/producer\%2F892131162.pdf.

Sarstedt, M., Ringle, C. M., Smith, D., Reams, R., \& Hair, J. F. (2014). Partial least squares structural equation modeling (PLSSEM): A useful tool for family business researchers. Journal of Family Business Strategy, 5(1), 105-115.

https://doi.org/10.1016/j.jfbs.2014.01.002

Schubert, T. F. (2016). Aplicação de conceitos de infraestrutura verde na definição de critérios para rede cicloviária (Monografia de Trabalho Final). Curso de Engenharia de Infraestrutura, Universidade Federal de Santa Catarina, Santa Catarina.

Segadilha, A. B. P., \& Sanches, S. da P. (2012). Fatores que Influenciam na Escolha da Rota pelos Ciclistas e seus Métodos de Identificação. In Anais do III Simpósio de Pós-Graduação em Engenharia Urbana (Simpgeu) (244-271). Maringá: SIMPGEU.

Silva, R. B. da. (2015). Avaliação do Sistema Cicloviário do Distrito Federal e Propostas para seu Desenvolvimento. 20oongresso Brasileiro de Transporte e Trânsito - ANTP (p.13). Santos: ANTP.

SLoCaT. (2018). Transport and Climate Change Global Status Report: Global Status Report. Recuperado em 20 de janeiro de 2019, de http://slocat.net/tcc-gsr

SMART PLS 3.0. (2018). Partial Least Squares. Estructural Equation Modeling. Recuperado em 12 de março de 2018, de https://www.smartpls.com/

Sorton, A., \& Walsh, T. (1994). Bicycle Stress Level as a Tool to Evaluate Urban and Suburban Bicycle Compatibility. Transportation Research Board, 1438, 17-24. Recuperado em 15, junho de 2017 em http://onlinepubs.trb.org/Onlinepubs/trr/1994/1438/1438-003.pdf.

Sousa, P. B. de. (2012). Análise de Fatores que Influem no Uso da bicicleta para Fins de Planejamento Cicloviário (Tese de Doutorado). Escola de Engenharia de São Carlos, Universidade de São Paulo, São Paulo.

Sun, L., Zhou, X., \& Sun, Z. (2019). Improving Cycling Behaviors of Dockless Bike-Sharing Users Based on an Extended Theory of Planned Behavior and Credit-Based Supervision Policies in China. Frontiers in Psychology, 10(2189).

doi: https://doi.org/10.3389/fpsyg.2019.02189

Tenenhaus, M. (1998). La régression PLS, théorie et pratique. Paris: Editions Technip.

Terch, S. H., \& Cao, K. (2018). GIS-MCDA based cycling paths planning: a case study in Singapore. Applied Geography, 94, 107-118. doi: https://doi.org/10.1016/j.apgeog.2018.03.007

Useche, S. A., Montoro, L., Tomas, J. M., \& Cendales, B. (2018). Validation of the Cycling Behavior Questionnaire: A tool for measuring cyclists' road behaviors. Transportation Research Part F: Traffic Psychology and Behaviour, 58, 1021-1030. https://doi.org/10.1016/j.trf.2018.08.003 
Vansteenkiste, P., Zeuwts, L., van Maarseveen, M., Cardon, G., Savelsbergh, G., \& Lenoir, M. (2017). The implications of low quality bicycle paths on the gaze behaviour of young learner cyclists. Transportation Research Part F: Traffic Psychology and Behaviour, 48, 52-60. https://doi.org/10.1016/j.trf.2017.04.013

Velloso, M. S. (2015). Planejamento cicloviário do Distrito Federal - Passado, Presente e Futuro. Brasília: Companhia de Planejamento do Distrito Federal, CODEPLAN. Recuperado em 01 de outubro de 2019, de http://www.codeplan.df.gov.br/wp-content/uploads/2018/02/TD_2_Planejamento_Ciclovi\%C3\%A1rio_no_DF.pdf

Winters, M., Davidson, G., Kao, D., \& Teschke, K. (2011). Motivators and deterrents of bicycling: comparing influences on decisions to ride. Transportation, 38, 153-168. doi: https://doi.org/10.1007/s11116-010-9284-y

Yang, Y., Wu, X., Zhou, P., Gou, Z., \& Lu, Y. (2019). Towards a cycling-friendly city: An updated review of the associations between built environment and cycling behaviors (2007-2017). Journal of Transport \& Health, 14, 100613. doi: https://doi.org/10.1016/j.jth.2019.100613

Zhou, B., Liu, T., Ryan, C., Wang, L., \& Zhang, D. (2020). The satisfaction of tourists using bicycle sharing: a structural equation model - the case of Hangzhou, China. Journal of Sustainable Tourism, 28(7), 1063-1082. doi: https://doi.org/10.1080/09669582.2020.1720697

Editor responsável: Fabio Duarte

Recebido: 26 ago. 2020

Aprovado: 24 jul. 2021 